\title{
Correction to: Modified repetitive learning control with unidirectional control input for uncertain nonlinear systems
}

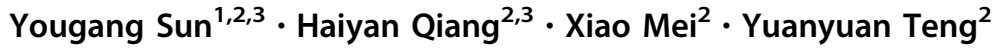

Published online: 27 July 2018

(C) The Natural Computing Applications Forum 2018

\section{Correction to: Neural Comput \& Applic DOI https://doi.org/10.1007/ s00521-017-2983-y}

The first affiliation of the author Yougang Sun should be "National Maglev Transportation Engineering R\&D Center, Tongji University", which can be found as follows:

${ }^{1}$ National Maglev Transportation Engineering R\&D Center, Tongji University, Shanghai, 201804, China

${ }^{2}$ College of Logistics Engineering, Shanghai Maritime University, Shanghai, 201306, China

\author{
${ }^{3}$ School of Mechanical Engineering, Tongji University, \\ Shanghai, 201804, China \\ and the acknowledgement text of the article should be:
}

Acknowledgement This work was supported in part by the National Key R\&D Program of China "Research on Key Technologies of Maglev Transportation System" (2016YFB1200600) and the National Natural Science Foundation of China (grant no. 51505277).

The original article can be found online at https:// doi.org/10.1007/s00521-017-2983-y.

Yougang Sun

1989yoga@tongji.edu.cn

1 National Maglev Transportation Engineering R\&D Center, Tongji University, Shanghai 201804, China

2 College of Logistics Engineering, Shanghai Maritime University, Shanghai 201306, China

3 School of Mechanical Engineering, Tongji University, Shanghai 201804, China 